\title{
Coalescence growth mechanism of inserted tin dioxide belts in polycrystalline $\mathrm{SnO}_{2}$-based ceramics
}

\author{
Mateus G. Masteghin, Rafael C. Bertinotti, Marcelo O. Orlandi* \\ Chemistry Institute, São Paulo State University, Araraquara, São Paulo, Brazil
}

\section{A R T I C L E I N F O}

\section{Keywords:}

A) $\mathrm{SnO}_{2}$

A) Varistor

B) Coalescence

B) Ostwald-ripening

C) Growth mechanism

D) Electron microscopy

\begin{abstract}
A B S T R A C T
$\mathrm{SnO}_{2}$-based varistors have been considered promising technological devices. However their practical application is usually stated as limited to high voltage circuits based on the high breakdown electric field exhibited by these ceramics. Recently, authors have shown that the insertion of one-dimensional (1D) $\mathrm{SnO}_{2}$ belts allows overcoming this limitation. In this work, we present a detailed study of the growth mechanism of the belts inside varistors using electron microscopy techniques. We were able to show that mass transport has an intrinsic dependence on the sintering time and requires similar crystalline structure between the belts and the matrix. Dual beam and high-resolution transmission electron microscopy techniques permitted determining that 3D growth of belts occurs by coalescence.
\end{abstract}

\section{Introduction}

It is well established that there is a close relationship between microstructure and electrical properties in polycrystalline electroceramics, especially in varistors [1-6] - a special class of ceramics presenting a nonlinear relationship between the applied potential and the resulting current [7]. When dealing with varistors, the grain size distribution has a major role determining the breakdown electric field $\left(E_{b}\right)$, i.e., the point at which a small change in the applied voltage generates a large variation in the current passing through the device. On the other hand, changing the average grain size of varistors can alter other parameters of the device [8].

Recently, the authors introduced an elegant way to decrease the breakdown electric field in $\mathrm{SnO}_{2}$-based varistors, still maintaining good nonlinear coefficient values [9]. For this, it was necessary to add $1 \%$ by weight of tin dioxide belts in the composition, allowing the three-dimensional growth of the belts during sintering, which reduces the number of potential barriers between the electrodes. However, the growth mechanism of the belts was not completely elucidated until this work.

During the sintering of a polycrystalline material, the densification process occurs concomitantly with the coarsening progression. Coarsening is responsible for the grain growth at the third stage of sintering, and it is guided by an energetic difference across an interface [10]; one should note that, for the single-phase $\mathrm{SnO}_{2}-\mathrm{CoO}-\mathrm{Cr}_{2} \mathrm{O}_{3}-\mathrm{Nb}_{2} \mathrm{O}_{5}$ ceramic, the interfaces can be understood as the grain boundaries. However, besides this conventional coarsened grain growth, the authors have shown that the insertion of single crystal $\mathrm{SnO}_{2}$ belts caused "giant grains" to emerge from the added belts, well beyond the average particle size [9].

Two mechanisms could be responsible for the exaggerated growth of these grains, the abnormal grain growth (AGG) or the coalescence, while this last one fits the more general Ostwald ripening definition, initially described as progressive growth in colloidal size at the expense of the decrease in the number of colloidal particles [11].

Abnormal grain growth is typically found in samples containing grain boundaries initially faceted, unlike normal grain growth in which grains are originally spherical. Precisely, because the grain growth is guided by energy differences between grain boundaries when they are faceted, and consequently anisotropic - with different energies depending on the orientation -, they can induce the abnormal grain growth [12-14]. Even faceting being the most common reason for AGG, several factors can influence this mechanism, such as temperature [14], doping [15], or oxygen partial pressure [16]. One noteworthy point is that abnormal grain growth happens when an initial monomodal particle size distribution results in a final bimodal distribution [17].

Coalescence can be triggered by the difference in the grain size, where larger grains absorb the smaller ones eliminating a shared grain boundary (interface). The driven force for this process is also given by an energetic difference between grains, being this progression favored when the degree of contact between the particles occurs with a low crystallographic disorientation [10]. Moreover, this mechanism is facilitated in a system in which particles rotation is free, such as suspended particles $[18,19]$. In a system initially presenting a bimodal

\footnotetext{
* Corresponding author.

E-mail address: orlandi@iq.unesp.br (M.O. Orlandi).
} 


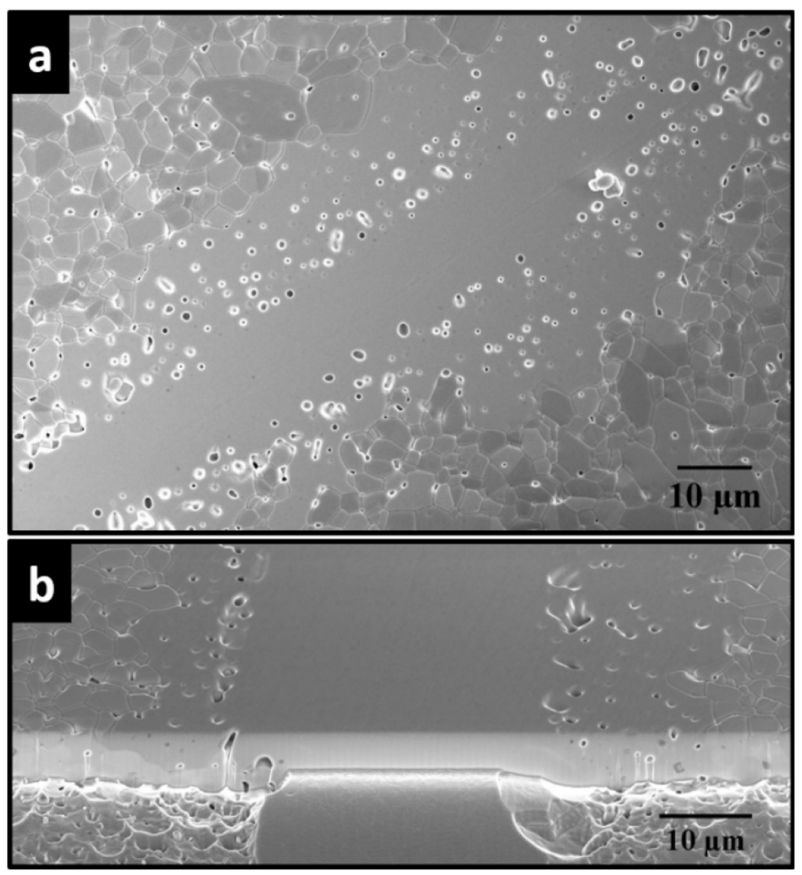

Fig. 1. Secondary electron (SE-SEM) images of the $\mathrm{SnCo}_{1.0} \mathrm{CrNb}_{0.05}$ system with $1 \mathrm{wt} \%$ of inserted $\mathrm{SnO}_{2}$ belts after sintering for $2 \mathrm{~h}$ at $1300^{\circ} \mathrm{C}$, showing: 1a) twodimensional growth of a belt. $1 \mathrm{~b}$ ) cross section revealing the three-dimensional growth of the belt.

distribution, this mechanism can be considered as a stimulated coarsening, in which the resulting particle size retains the initial distribution behavior but shifted to larger average size values.

In this work, the authors studied in detail the growth mechanisms of tin dioxide belts inserted in a $\mathrm{SnO}_{2}$-based varistor system using electron microscopy techniques. To the best of our knowledge, this is the first time this growth mechanism is reported in a system with a low degree of particle mobility, that is, in dense polycrystalline ceramics.

\section{Material and Methods}

To perform this study, authors used pure tin dioxide belts synthesized by carbothermal reduction method inserted in a typical $\mathrm{SnO}_{2}$ based varistor compositions. The carbothermal reduction process consists of mixing a carbon source to the starting oxide in order to increase the oxide vapor pressure at high temperature. Thus, the $\mathrm{SnO}_{2}$ (SigmaAldrich, 99.9\% purity) and the carbon black (Union Carbide, >99\% purity) were mixed in the molar ratio of $1.5: 1$, and $1 \mathrm{~g}$ of this mixture was dropped on alumina crucible that was inserted in the middle of a tube furnace kept at $1135^{\circ} \mathrm{C}$ for $75 \mathrm{~min}$. During the synthesis, a constant flux of $\mathrm{N}_{2}(150 \mathrm{sccm})$ was used and, in order to obtain pure $\mathrm{SnO}_{2}$ belts, above $900^{\circ} \mathrm{C}$ an oxygen counter flow of $5 \mathrm{sccm}$ was delivered and maintained until the end of the process [adapted from Ref. 20]. We also tested the insertion of indium tin oxide (ITO) belts in the same varistor composition for comparison purposes, and the ITO belts were synthesized by the carbothermal reduction route as well, using the co-evaporation method [21].

The studied matrix compositions were $(98.90 \%) \mathrm{SnO}_{2}-(1.00 \%) \mathrm{CoO}-$ $(0.05 \%) \mathrm{Cr}_{2} \mathrm{O}_{3}-(0.05 \%) \mathrm{Nb}_{2} \mathrm{O}_{5}$, and $(99.65 \%) \mathrm{SnO}_{2}-(0.20 \%) \mathrm{CoO}-$ $(0.05 \%) \mathrm{Cr}_{2} \mathrm{O}_{3}-(0.10 \%) \mathrm{Nb}_{2} \mathrm{O}_{5}$, all in molar percentage, hereinafter called $\mathrm{SnCo}_{1.0} \mathrm{CrNb}_{0.05}$ and $\mathrm{SnCo}_{0.2} \mathrm{CrNb}_{0.1}$, respectively. The powder mixture was homogenized using a ball milling in alcohol medium. After homogenization, the powder was forced to pass through a 200-mesh sieve and then mixed with $1 \mathrm{wt} \%$ of $\mathrm{SnO}_{2}$ single crystalline belts or $1 \mathrm{wt}$ $\%$ of ITO single crystalline belts. Then, the powders were compacted in cylindrical discs and sintered in room atmosphere at $1300^{\circ} \mathrm{C}$ for 15,30 , 60,90 and $120 \mathrm{~min}$ with a heating and cooling rate of $10^{\circ} \mathrm{C} \cdot \mathrm{min}^{-1}$.

The morphological characteristics of all samples, including crosssection images and the 3D reconstruction (with the aid of the Slice and View $^{\circledR}$ and Avizo $^{\circledR}$ software), were held on a dual beam microscope (FEI, model Helios NanoLab 600i), equipped with a micromanipulator (Easy-Lift), and trimethyl(methylcyclopentadienyl)platinum(IV) gas injection system (Pt-GIS). A thin lamella $(12 \mu \mathrm{m} \times 5 \mu \mathrm{m} \times 80 \mathrm{~nm})$ from the sample sintered for $2 \mathrm{~h}$ was prepared to contain the original $\mathrm{SnO}_{2}$ belt, grown region, and grains interfaces, and studied in detail at the transmission electron microscope (TEM - Phillips, model CM200).

\section{Results and Discussion}

Fig. 1a shows the 2D growth of the belt after sintering for $2 \mathrm{~h}$. The SEM image shows that the belt grew both laterally and vertically at the same proportion. Although different belts may present distinct growth rates based on the initial size, the belt has maintained their main role to eliminate shared grain boundaries and, thus, common potential barriers [22]. Consequently, there is no evidence of a more energetic interface, such as a faceted or a twin boundary, capable and responsible for stimulating their growth $[13,23,24]$, raising the idea of a dominating coalescence growth mechanism.

One can see that the belt in Fig. 1a exhibited a considerable side growth, especially in the top-right section. However, this high grain boundary elimination rate resulted in a substantial amount of intragranular pores. This is another evidence for the coalescence mechanism, in which parts of the belt surrounded by the highest amount of grains with a lower degree of crystallographic disorientation will be the one with the largest growth rate, responsible for the fast elimination of grain boundaries that would be sinks for the pores elimination [25].

Fig. 1b shows a cross-section image of a typical belt where it is possible to observe the three-dimensional growth of the belt and rounded outer boundaries, unlike the faceted grains usually observed for AGG mechanism [12-15].

For a more comprehensive spatial view of how three-dimensional growth occurs, tomography images are shown in Fig. 2 (at different perspectives) after the $3 \mathrm{D}$ reconstruction of a belt grown in the $\mathrm{SnCo}_{0.2} \mathrm{CrNb}_{0.1}$ system. Fig. $2 \mathrm{a}-\mathrm{b}$ (also see the Video at $\mathrm{SI}$ ) shows that even with the system presenting a considerable number of pores, the original belt remains completely pore-free, indicating that the phenomenon occurs only at the interface and towards the grains.

In order to monitor the growth of the belts over time, the same belts were observed before and after the sintering process for 15, 30, 60, 90, and $120 \mathrm{~min}$, as shown in Fig. 3a-e, respectively. Fig. 3a shows that for low sintering time, the belt started the process of incorporating smaller grains in a barely perceptible way, since the mass transport is still limited. For samples sintered at 30 and $60 \mathrm{~min}$ (Fig. $3 \mathrm{~b}$ and c, respectively), the mass transport process starts becoming evident at the edges of the belt, once they are enclosed by a greater amount of grains, and the energy gradient is more pronounced. It is observed that belts are working as large grains encompassing the smaller ones, which is a typical coalescence process.

Observing the sample sintered for $90 \mathrm{~min}$ (Fig. 3d) it is noticed that the belt has already grown and incorporated the neighboring grains throughout its volume. Comparing Fig. 3e (120 min sintering time) and Fig. 3d, it is clear that the growth rate of the belt has increased along the sintering time, reaching $>50 \mu \mathrm{m}$ of width (about ten times its initial 

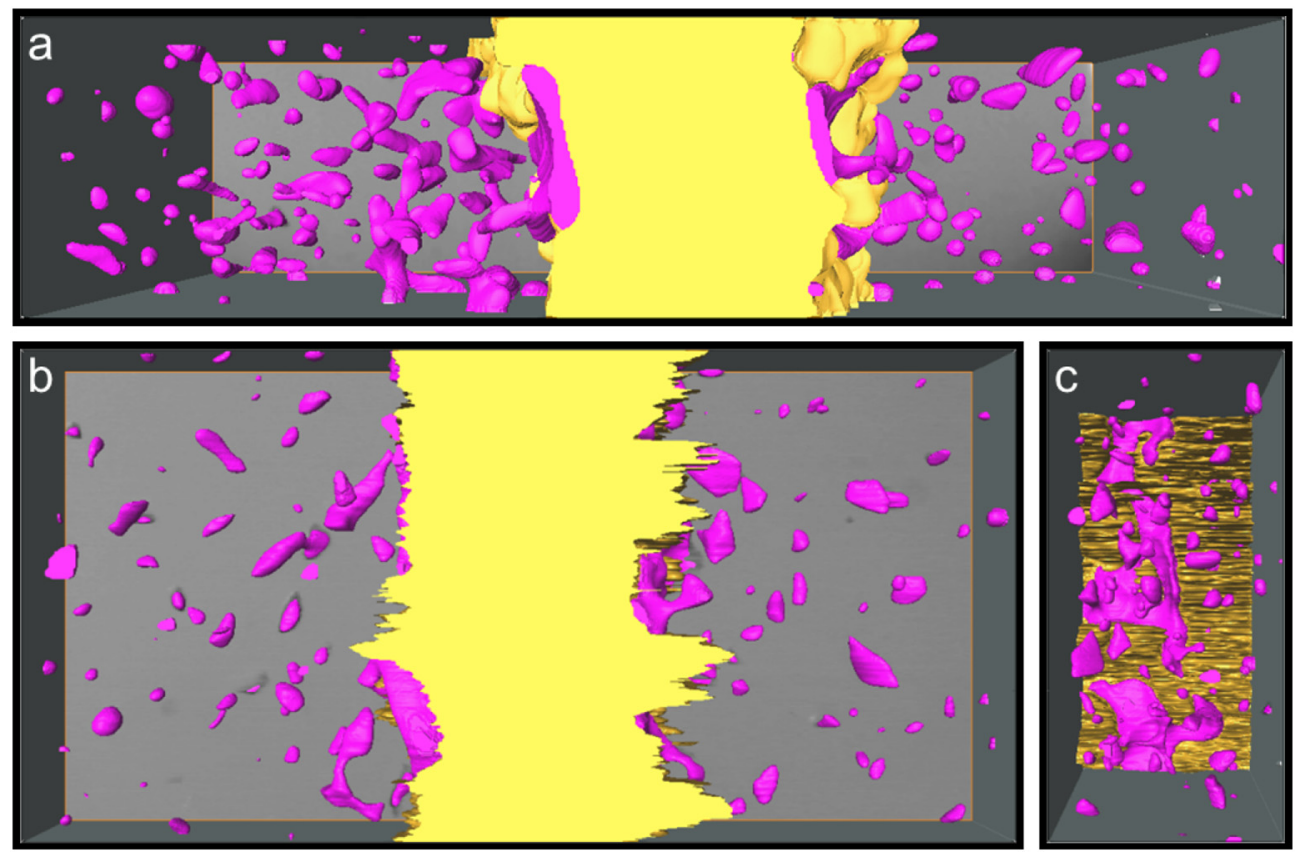

Fig. 2. Tomography of the $\mathrm{SnCo}_{0.2} \mathrm{CrNb}_{0.1}$ system with $1 \mathrm{wt} \%$ of added $\mathrm{SnO}_{2}$ belts, sintered for $2 \mathrm{~h}$ at $1300{ }^{\circ} \mathrm{C}$, showing the a) $\mathrm{XY}$ b) $\mathrm{XZ}$, and c) $\mathrm{YZ}$ perspectives. The pink surfaces represent the pores. (For interpretation of the references to color in this figure legend, the reader is referred to the web version of this article.)

size). This is related to the direct relationship between the growth rate and the driving force, i.e., with the size difference between grains and belts [12].

Using an image processing software, the analysis of the belts lateral growth before and after different sintering times was performed quantitatively. Fig. 4a-b show the belt from Fig. 3c, at the same magnification and vertically aligned, before (blue colored) and after $60 \mathrm{~min}$ of sintering time (red colored). The difference in percentage between the red and blue colored areas was recorded for this belt and the same procedure was used for the other sintering times. The plot of percentage area variation versus sintering time is shown in Fig. 4c.

Fig. 4c shows an exponential increase of the area difference as a function of the sintering time, as has already been shown to be true for coalescence growth processes [26]. Note that the value showed for $120 \mathrm{~min}$ was obtained through the exponential fit equation: $\triangle$ Area $(\%)=88.4+36.5 * e^{0.03 * \text { Time (Min) }}$, once the grown belt did not fit the horizontal field width of the SEM image.

In order to further investigate into the belt growth process and the grain alignment, FIB was used to prepare a lamella containing the original belt, the belt/grains boundaries, and the original grains. Fig. 5a shows a low magnification image of the lamella, where blue represents the original belt, the coalescent grain is in red, and disoriented grains region is in grayscale.

Fig. 5b shows a high-resolution image (HRTEM) and the selected area diffraction (SAD) of the original belt region indicated in Fig. 5a (in blue). The interplanar distances and angles can be completely indexed with the rutile $\mathrm{SnO}_{2}$ crystal structure (JCPDS \#41-1445) [27], which is the same crystalline structure of $\mathrm{SnO}_{2}$-based varistor grains. Moreover, one can observe that the growth of the belts by coalescence does not cause any type of line defect, but it has generated intragranular porosity due to the high grain boundary mobility.

Fig. 5c, which is an HRTEM image of point "c" in Fig. 5a, shows the interface of the grown belt with an adjacent grain. The plane with distance $0.24 \mathrm{nn}$ (200) can be seen in the original belt (Fig. 5b), and on both sides of the grown belt (Fig. 5c), but grains are not completely aligned since (101) interplanar distance is not observed on the other grain (right side of Fig. 5c), thus generating a grain boundary. Based on the HRTEM images the belts grow in the [101] direction, which agrees with previous studies [28]. Moreover, the growth in this [101] direction minimizes the crystal energy [28], so it is preferential.

The point labeled as "d" in Fig. 5a is shown in high resolution in Fig. 5d. Again, on its left, the coalescent grain has the same orientation as the original belt [(101) plane is indexed], which reinforces that the (101) plane is inducing the alignment of the grain located on the right side of Fig. 5d, besides allowing this growth region to partially remove the interface with the grain in another orientation (right side of Fig. 5d). It is possible to predict that longer sintering times would have caused the entire region shown in Fig. $5 \mathrm{~d}$ to exhibit the same orientation without the presence of any grain boundary.

Based on what was exposed above, it is expected that no coalescence process will occur if matrix and belts present different crystalline structures. To test this possibility, we also incorporated $1 \mathrm{wt} \%$ of ITO (cubic structure) [29] belts at the $\mathrm{SnCo}_{1.0} \mathrm{CrNb}_{0.05}$ system (tetragonal structure) [27]. It would be interesting from the electrical point of view since ITO exhibits considerable lower electrical resistance than $\mathrm{SnO}_{2}$ [30]. Fig. 6a presents a region with the ITO belt trapped on the surface of the material by van der Waals force after being removed from its initial position during the polishing process. It is observed that ITO belts keep the regular shape, and has no indication of coalescence process, while the $\mathrm{SnCo}_{1.0} \mathrm{CrNb}_{0.05}$ grains present normal grain growth and densification.

Fig. $6 \mathrm{~b}$ exhibits the region where an ITO belt was removed from the material. Once more, the shape of the belt sculpted in the varistor grains indicates no mass transport between the $\mathrm{SnO}_{2}$-based grains and the ITO belts. As it was expected for the coalescence process, more important than having the presence of "large grains" (the belts) in the material is having belts with the same crystalline structure of the grains, enabling the orientation of structures which will result in grain 

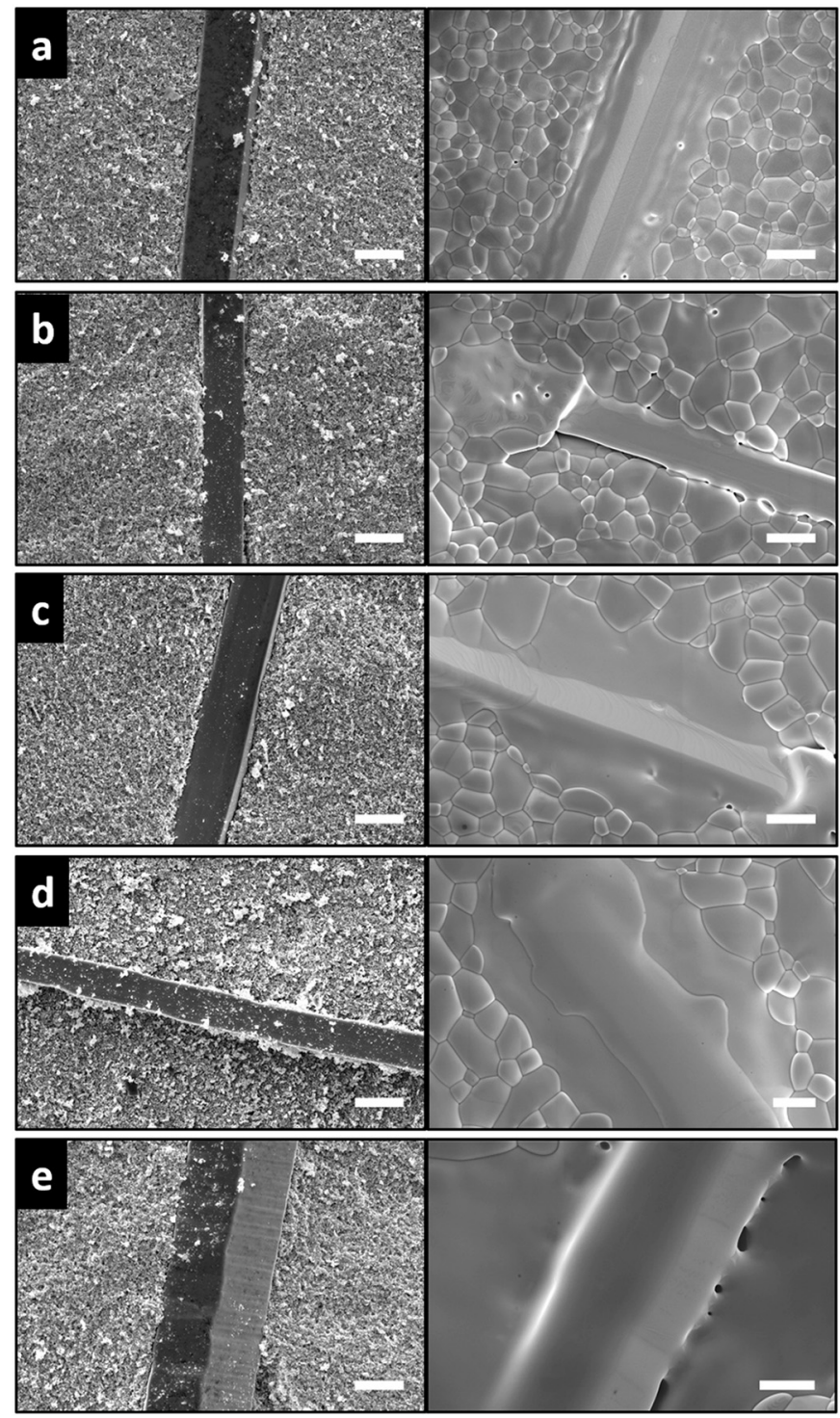

Fig. 3. SEM images of selected belts in the $\mathrm{SnCo}_{1.0} \mathrm{CrNb}_{0.05}$ system before and after sintering time using a) 15 b) 30 c) 60 d) 90 and e) 120 min at maximum temperature. Scale bars measure $5 \mu \mathrm{m}$.

boundaries elimination. In the case of materials with so distinct phases, such as $\mathrm{SnO}_{2}$ and ITO, there is no net effect trying to use 1D structures to eliminate grain boundaries.

In the present investigation, the authors showed that the growth of $\mathrm{SnO}_{2}$ 1D structures added to a tin dioxide matrix occurs through the coalescence mechanism, or more generally through Ostwald-ripening. As a result of this work, other combinations between polycrystalline matrices and unidimensional structures (for instance $\mathrm{ZnO}, \mathrm{TiO}_{2}, \mathrm{WO}_{3}$, etc.) can be designed to obtain the desired properties, as it was done in the present work aiming to reduce the number of potential barriers present in the grain boundaries of high-performance $\mathrm{SnO}_{2}$-based varistors. To achieve success, belts and grains must have the same crystalline structure to facilitate the mass transport.
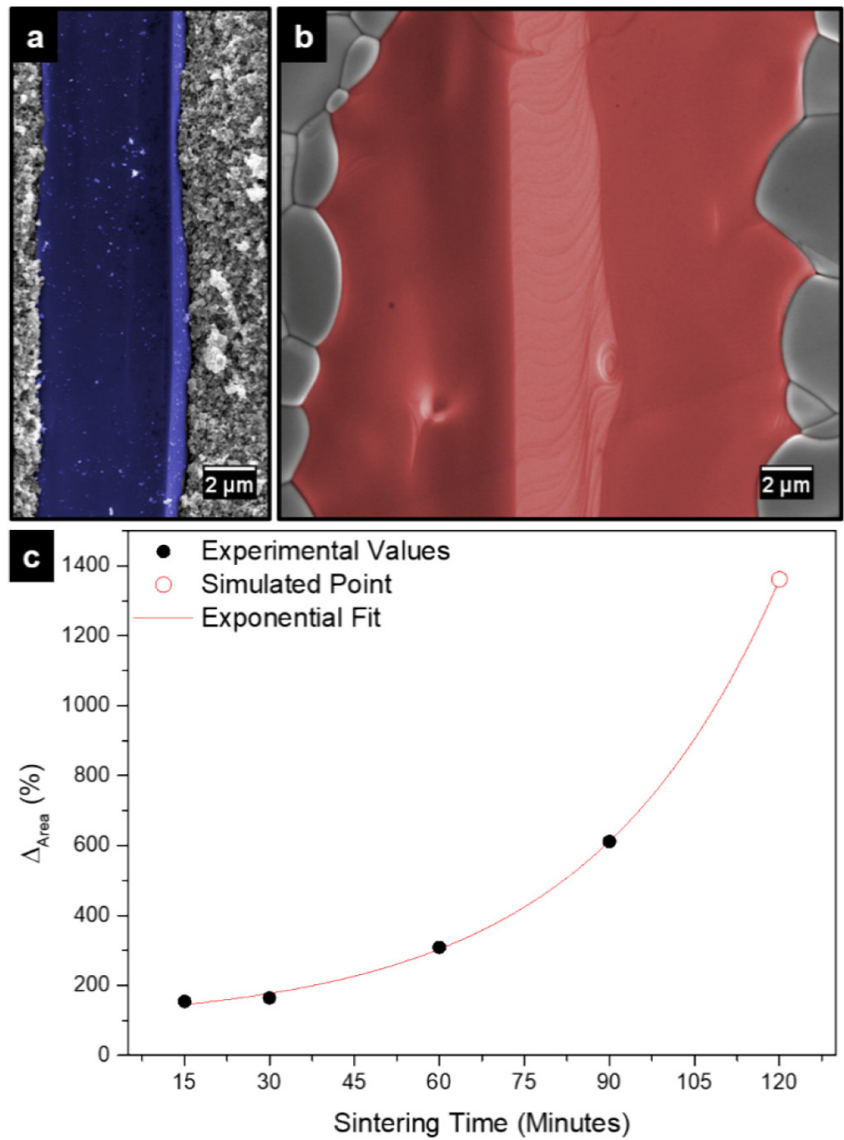

Fig. 4. a) Blue color represents the original belt already showed in Fig. 3c. b) The belt after $60 \mathrm{~min}$ of sintering time is indicated by the red color. c) Obtained percentage area difference vs sintering time plot, and the exponential fit. Filled black dots are experimental values, and the open red circle was obtained through the exponential fit equation. (For interpretation of the references to color in this figure legend, the reader is referred to the web version of this article.)

\section{Conclusions}

The present work studied the three-dimensional growth of $\mathrm{SnO}_{2}$ belts incorporated in a $\mathrm{SnO}_{2}$-based matrix. Different growth mechanisms were tested and experimental results show that the large belts induce the crystallographic alignment of matrix grains during sintering, eliminating grains boundaries and promoting intragranular porosity. The obtained results agree with the coalescence mass transport mechanism. Cross-section and tomography images showed that the singlecrystalline $\mathrm{SnO}_{2}$ belts grew in all directions incorporating smaller grains, and SEM images before and after different sintering times indicated a growth rate governed by the size difference between grains and belts. High-resolution TEM analysis proved that incorporated grains have the same crystallographic orientation as the belts, and adjacent grains tend to align to be incorporated. The importance of $1 \mathrm{D}$ structures and grains having the same crystalline structure to allow the coalescence growth process is also discussed.

Supplementary data to this article can be found online at https:// doi.org/10.1016/j.matchar.2018.05.027. 


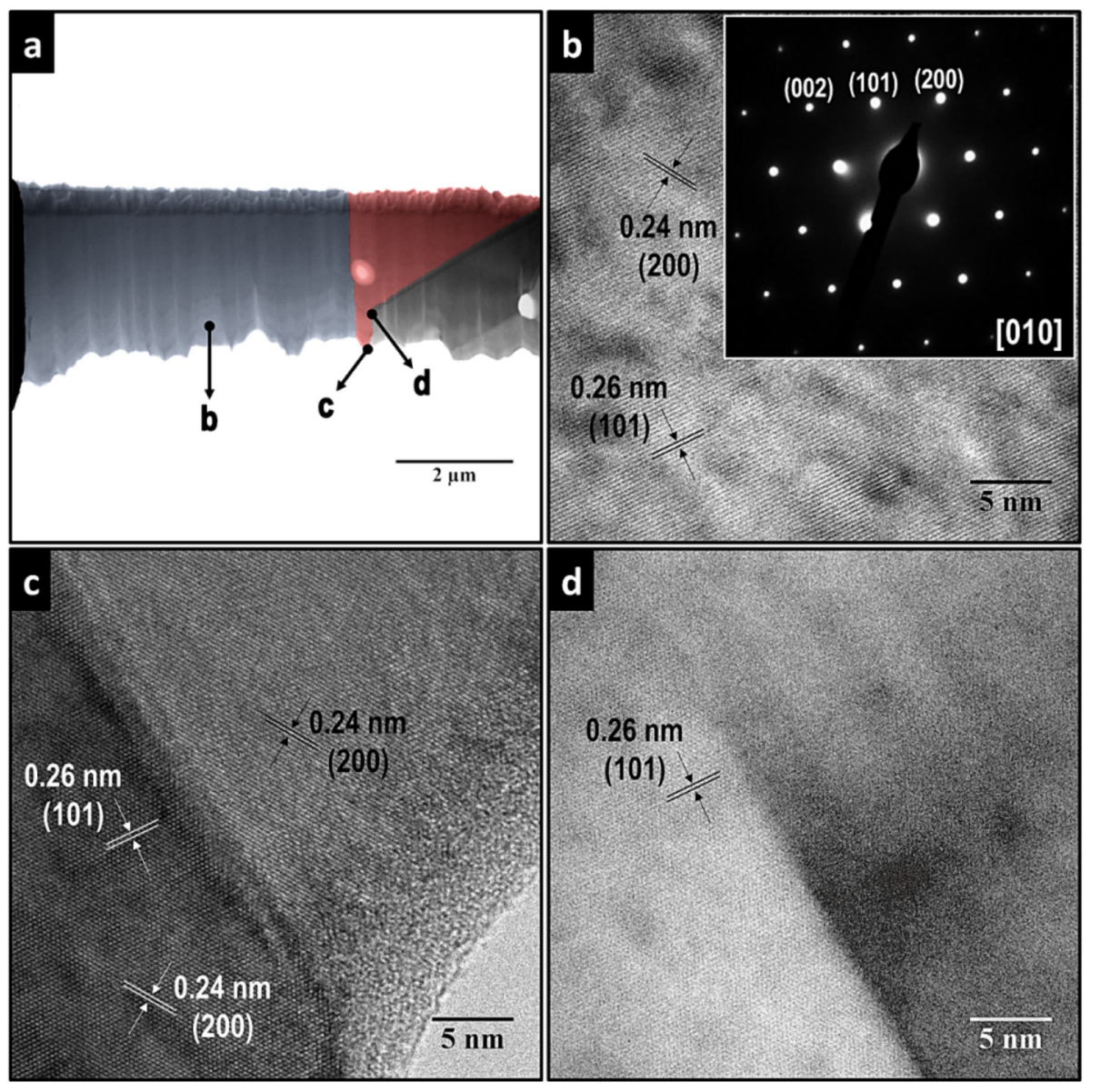

Fig. 5. a) Low magnification TEM image of the lamella containing the original $\mathrm{SnO}_{2}$ belt (blue color), the growth region (red color), and the grains (grayscale). b) HRTEM and SAD images of the original belt region. c) HRTEM image showing the belt/ grain interface. d) HRTEM image of point "d". (For interpretation of the references to color in this figure legend, the reader is referred to the web version of this article.)
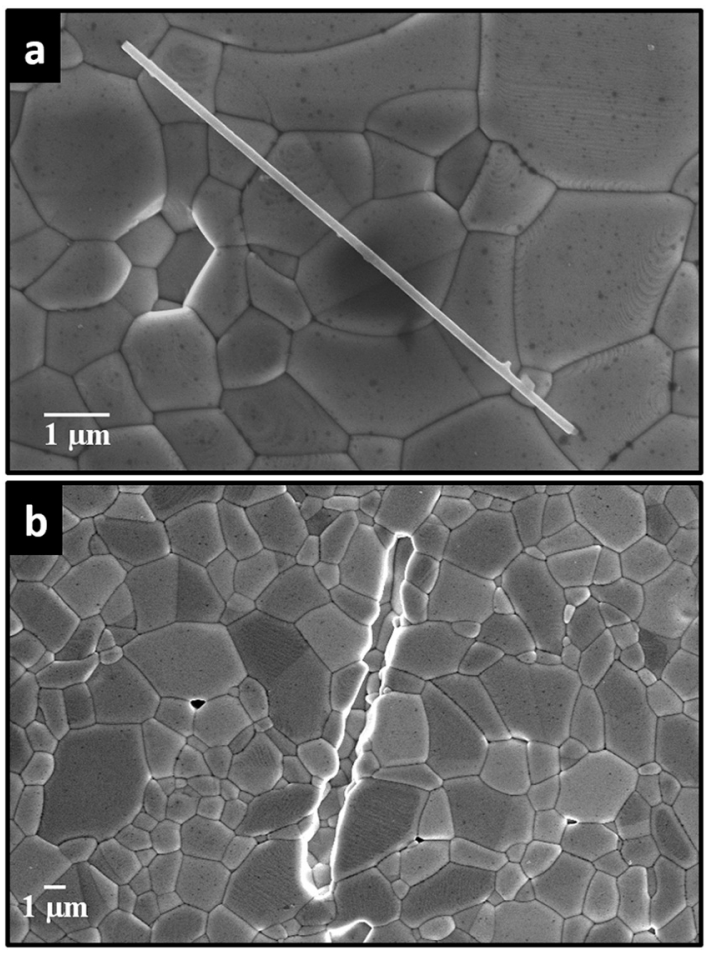

Fig. 6. Secondary electron (SE-SEM) images of a) an original ITO belt expelled from the matrix after sintering, that remained attached to the surface probably due to van der Waals forces, and b) a region that originally contained an ITO belt into the (98.90\%) $\mathrm{SnO}_{2}-(1.00 \%) \mathrm{CoO}-(0.05 \%) \mathrm{Cr}_{2} \mathrm{O}_{3}-(0.05 \%) \mathrm{Nb}_{2} \mathrm{O}_{5}$ matrix with $1 \mathrm{wt} \%$ of inserted ITO belts after sintering for $2 \mathrm{~h}$ at $1300^{\circ} \mathrm{C}$.

\section{Acknowledgments}

The authors would like to thank the funding agencies FAPESP [proc. \#2013/07296-2, \#2015/21033-0, \#2015/50526-4] and CNPq [proc. \#447760/2014-9, \#800733/2014-2, \#303542/2015-2, \#443138/ 2016-8]. We appreciate the support of Mr. Rick Passey with Avizo ${ }^{\circledast}$ software.

\section{Data Availability}

The raw data required to reproduce these findings are available to download from here.

\section{References}

[1] J. Wong, Microstructure and phase transformation in a highly non-Ohmic metal oxide varistor ceramic, J. Appl. Phys. 46 (1975) 1653-1659.

[2] S.A. Pianaro, P.R. Bueno, E. Longo, J.A. Varela, Microstructure and electric properties of a $\mathrm{SnO}_{2}$ based varistor, Ceram. Int. 25 (1999) 1-6.

[3] G. Hu, J. Zhu, H. Yang, Effect of $\mathrm{CuO}$ addition on the microstructure and electrical properties of $\mathrm{SnO}_{2}$-based varistor, J. Mater. Sci. Mater. Electron. 24 (2013) 2944-2949.

[4] O.A. Desouky, K.E. Rady, Synthesis, structure and dielectric properties of nanocrystalline $\mathrm{SnO}_{2}-\mathrm{CoO}-\mathrm{Nb}_{2} \mathrm{O}_{5}$ varistor doped with $\mathrm{Cr}_{2} \mathrm{O}_{3}$, J. Mater. Sci. Mater. Electron. 28 (2017) 1-7.

[5] M.M. Shahraki, M. Golmohammad, I. Safaee, M.D. Chermahini, The control of abnormal grain growth in low-voltage $\mathrm{SnO}_{2}$ varistors by microseed addition, Ceram. Int. 44 (2018) 3388-3393.

[6] M.G. Masteghin, M.O. Orlandi, Grain-boundary resistance and nonlinear coefficient correlation for $\mathrm{SnO}_{2}$-based varistors, Mater. Res. 19 (2016) 1286-1291.

[7] D.R. Clarke, Varistor ceramics, J. Am. Ceram. Soc. 82 (1999) 485-502.

[8] P.A. Santos, S. Maruchin, G.F. Menegoto, A.J. Zara, S.A. Pianaro, The sintering time influence on the electrical and microstructural characteristics of $\mathrm{SnO}_{2}$ varistor Mater. Lett. 60 (2006) 1554-1557.

[9] M.G. Masteghin, J.A. Varela, M.O. Orlandi, Controlling the breakdown electric field in $\mathrm{SnO}_{2}$ based varistors by the insertion of $\mathrm{SnO}_{2}$ nanobelts, J. Eur. Ceram. Soc. 37 
(2017) 1535-1540.

[10] R.M. German, Coarsening in sintering: grain shape distribution, grain size distribution, and grain growth kinetics in solid-pore systems, Crit. Rev. Solid State Mater. Sci. 35 (2010) 263-305.

[11] P.W. Voorhees, The theory of Ostwald ripening, J. Stat. Phys. 38 (1985) 231-252.

[12] Y.J. Park, N.M. Hwang, D.Y. Yoon, Abnormal growth of faceted (WC) grains in a (Co) liquid matrix, Metall. Mater. Trans. A 27 (1996) 2809-2819.

[13] B.K. Lee, S.Y. Chung, S.J.L. Kang, Grain boundary faceting and abnormal grain growth in $\mathrm{BaTiO}_{3}$, Acta Mater. 48 (2000) 1575-1580.

[14] S.B. Lee, D.Y. Yoon, N.M. Hwang, M.F. Henry, Grain boundary faceting and abnormal grain growth in nickel, Metall. Mater. Trans. A 31 (2000) 985-994.

[15] I. Bae, S. Baik, Abnormal grain growth of alumina, J. Am. Ceram. Soc. 80 (1997) 1149-1156.

[16] A.A. Felix, V.D.N. Bezzon, M.O. Orlandi, D. Vengust, M. Spreitzer, E. Longo, D. Suvorov, J.A. Varela, Role of oxygen on the phase stability and microstructure evolution of $\mathrm{CaCu}_{3} \mathrm{Ti}_{4} \mathrm{O}_{12}$ ceramics, J. Eur. Ceram. Soc. 37 (2017) 129-136.

[17] P.R. Rios, Abnormal growth in the presence of coarsening particles, Acta Metall. Mater. 40 (1992) 649-651.

[18] C. Ribeiro, E.J.H. Lee, T.R. Giraldi, R. Aguiar, E. Longo, E.R. Leite, In situ oriented crystal growth in a ceramic nanostructured system, J. Appl. Phys. 97 (2005) 22-25.

[19] P. Shen, W.H. Lee, (111)-specific coalescence twinning and martensitic transformation of tetragonal $\mathrm{ZrO}_{2}$ condensates, Nano Lett. 1 (2001) 707-711.

[20] P.H. Suman, M.O. Orlandi, Influence of processing parameters on nanomaterials synthesis efficiency by a carbothermal reduction process, J. Nanopart. Res. 13 (2011) 2081-20188.

[21] M.O. Orlandi, R. Aguiar, A.J.C. Lanfredi, E. Longo, J.A. Varela, E.R. Leite, Tin- doped indium oxide nanobelts grown by carbothermal reduction method, Appl. Phys. A Mater. Sci. Process. 80 (2005) 23-25.

[22] M.G. Masteghin, R.C. Bertinotti, M.O. Orlandi, High-performance and low-voltage $\mathrm{SnO}_{2}$-based varistors, Ceram. Int. 43 (2017) 13759-13764.

[23] A.D. Rollett, D.J. Srolovitz, M.P. Anderson, Simulation and theory of abnormal grain-growth anisotropic grain-boundary energies and mobilities, Acta Mater. 37 (1989) 1227-1240.

[24] S. Tominc, A. Recnik, Z. Samardzija, G. Drazic, M. odlogar, S. Bernik, N. Daneu, Twinning and charge compensation in $\mathrm{Nb}_{2} \mathrm{O}_{5}$-doped $\mathrm{SnO}_{2}-\mathrm{CoO}$ ceramics exhibiting promising varistor characteristics, Ceram. Int. 44 (2018) 1603-1613.

[25] J. Svoboda, H. Riedel, Pore-boundary interactions and evolution equations for the porosity and the grain size during sintering, Acta Mater. 40 (1992) 2829-2840.

[26] K.E.J. Lehtinem, M.R. Zachariah, Effect of coalescence energy release on the temporal shape evolution of nanoparticles, Phys. Rev. B 63 (2001) (2054021-205402-7).

[27] G. Mccarthy, J. Welton, X-ray diffraction data for $\mathrm{SnO}_{2}$. An illustration of the new powder data evaluation methods, Powder Diffract. 4 (1989) 156-159.

[28] Z.R. Dai, Z.W. Pan, Z.L. Wang, Ultra-long single crystalline nanoribbons of tin oxide, Solid State Commun. 118 (2001) 351-354.

[29] N.I. Kovtyukhova, T.E. Mallouk, Conductive indium-tin oxide nanowire and nanotube arrays made by electrochemically assisted deposition in template membranes: switching between wire and tube growth modes by surface chemical modification of the template, Nano 3 (2011) 1541-1552.

[30] E.P.S. Arlindo, J.A. Lucindo, C.M.O. Bastos, M.O. Orlandi, Electrical and optical properties of conductive and transparent ITO@PMMA nanocomposites, J. Phys. Chem. C 116 (2012) (12964-12952). 